\title{
THE IMPACT OF ORGANISATIONAL RESILIENCE ON CONSTRUCTION PROJECT SUCCESS: EVIDENCE FROM LARGE-SCALE CONSTRUCTION IN CHINA
}

\author{
Jie YANG, Qian CHENG $\mathbb{B}^{*}$ \\ School of Management Engineering, Shandong Jianzhu University, 250101 Jinan, China
}

Received 29 June 2020; accepted 8 October 2020

\begin{abstract}
Environmental uncertainty, social public events and increasing challenges has raised the urgency for the need to improve organisational resilience of construction projects, which is of great significance to the success and governance of construction projects. This study explores the organisational resilience factors that affect the success of construction projects based on a literature review and the actual situation and abstracts them into four explanatory variables: situation monitoring, organisational structure, organisational culture and participants. Through the crisp-set Qualitative Comparative Analysis (csQCA) method, 15 Chinese cases that meet the research conditions are compared and analysed, and two effective conditional configurations obtained. The results show that in the absence of timely monitoring of the changes in the situation, flexible organisational structure, cohesive organisational culture and participation of multiple subjects can promote the success of the construction project. The synergy of multiple participants can make up for the lack of organisational culture to a certain extent. Moreover, public participation and big data applications should be given full attention in the improvement of organisational resilience. This study can provide a basis for construction projects to reasonably match organisational resilience conditions to cope with crisis and challenges.
\end{abstract}

Keywords: organisational resilience, construction project, situation monitoring, organisational structure, organisational culture, participation, project management.

\section{Introduction}

In early 2020, the "COVID-19 Pandemic" spread indiscriminately in Wuhan, China. In the face of epidemic crisis, the rapid construction of Leishenshan (Thunder God Mountain) Hospital and Huoshenshan (Fire God Mountain) Hospital was a phenomenon that attracted close attention from the society and the construction industry. Faced with stringent time limit and strict standards, the two "safety island" hospitals, which could provide strong support to win the battle against the epidemic, rose at an amazing speed. The construction of these hospitals also reflects the organisational resilience of the construction project in a complex environment.

Due to natural disasters, social public events, etc., we are facing more and more uncertainties, so resilience has become a hot concept in recent years, such as infrastructure resilience (Brown et al., 2017; Cook, 2014; Patriarca et al., 2018), urban resilience (Masnavi et al., 2019), community resilience (Rapaport et al., 2018) and organisational resilience (Abdullah et al., 2013; Hillmann, 2020). The abovementioned hospitals generally referred to the "fishbone" layout used in constructing emergency field hospitals to reduce the risk of cross-infection, $5 \mathrm{G}$ and cloud platform technology to achieve smart medical care, uninterruptible power system (UPS) to provide emergency power supply and negative pressure systems to "navigate" airflow. From the construction process of the two hospital, it can be determined that the resilience of construction organisations in the new era does not depend on a single subject, nor does it depend on a single discipline (Jin \& Mostafavi, 2014).

The research on increasing the organisational resilience of construction projects has certain flaws. Past research has isolated mainly infrastructure and built environment from society (de Kloet et al., 2019). However, studying the infrastructure resilience construction within the social framework requires the connection of these two parties is crucial for improving the contribution of the built environment to community resilience (Haigh

*Corresponding author. E-mail: chengqian835988245@163.com 
\& Amaratunga, 2010). Under the social framework, the public is the largest actor. The public is the largest actor under the social framework. Public participation is widely used in developed countries as an effective approach to improve decision-making outcomes, public project execution and collaborative governance (Enserink \& Koppenjan, 2007). Public participation should also be considered in construction projects. For example, aafter the official opening of 5G, the first live broadcast signal on the construction site of Leishenshan Hospital was launched on January 26. As of January 29, the cumulative page views have exceeded 200 million. Tens of millions of people act as "cloud supervisors" of the network, fully reflecting the characteristics of "new stakeholders". The public has become the "new stakeholders" of project management in the Internet era $(\mathrm{Gu}, 2015)$. Therefore, public participation should also be considered as an important indicator to measure construction organisational resilience.

Organisational resilience often means that the organisation has the ability to withstand frequent interference and cope with new risks. Hamel and Välikangas (2003) defined organisational resilience as the ability to dynamically re-establish strategies and business models to cope with inevitable changes, so as to help the organisation overcome the adverse consequences of potential destructive impact. Woods and Wreathall (2008) thought that organisational resilience is not only an adaptive ability. From this point of view, they specifically distinguished two types of organisational adaptability: the first is that the organisation uses existing plans and capabilities to rebound; the second is that the organisation develops new capabilities to respond to the sudden dynamic environment. From the existing concept of organisational resilience, there are two tendencies. The first view regards organisational resilience as the ability to recover from adversity and recover from failure; the second view regards organisational resilience as the ability to transcend recovery, including the ability to keep up with or even create new development opportunities and expansion capabilities. Combining theory and practice, there are two understandings of the organizational resilience of construction projects: (1) The ability of the construction project itself to withstand, absorb, respond to and recover to the original state of emergencies (such as earthquake, fire, terrorist attack) stems from the original concept of resilience (Comfort, 1994). (2) The construction project organisation should not only have the ability to withstand emergencies, but also the adaptability to unexpected challenges, flexibility to restore normal state and the ability to prepare and learn from experience to deal with future challenges. The concept is broader in the face of higher requirements.

This study aims to explore the critical conditions of organisational resilience to improve construction project success and extract the corresponding key indicators through literature review combined with an analysis of the actual situation. Then, based on the understanding of or- ganisational resilience in the context of construction projects, 15 eligible and representative Chinese projects are selected to expound on the relationship between critical conditions of organisational resilience and project success with crisp-set Qualitative Comparative Analysis (csQCA) method. The findings of this work will not only enrich theoretical research of organisational resilience but also promote the development of engineering management industry in the complex and rapid development era.

\section{Literature review}

\subsection{The organisational resilience promotes the success of construction project}

Resilient organisation (Hatton et al., 2012) defined organisational resilience as the ability of an organisation to survive and thrive in a changing and uncertain environment. The construction sector is not only a key component of the nation's economy but also a primary factor in the quality of communities' lives and the ability of the government to achieve their policies (Bosher et al., 2007). With the outbreak of the epidemic, we also realize the importance of construction organisation for post-disaster recovery and reconstruction programs. Construction organisations must first have the resilience to deal with and rover from disasters to improve the resilience of communities (Wilkinson et al., 2016). Sapeciay et al. (2017) indicated construction organisations must be resilient to ensure the successful implementation of the post-disaster recovery and reconstruction plan, and organisational resilience promotes the success of construction project.

In the current research, the organisational resilience of the construction industry is embodied in resilience engineering, thus promoting the impact of organisational resilience on construction project success is gradually recognised. The current research incorporated the concept of safety and reliability into the understanding of resilience engineering and regarded safety as a positive thing (Dekker \& Hollnagel, 2007). Resilience engineering is a new method of thinking about problems and opportunities (Pellissier, 2010), as well as new concepts, tools and methods of evaluating flexibility and thinking about safety (Hollnagel et al., 2006). It pertains to how the capacity of organisations at all levels can be improved to build strong and flexible processes (Omidvar et al., 2017). Pellissier (2010) proposed organisational innovation can be promoted if the idea of resilience engineering is incorporated into the business foundation.

However, organisational resilience requires further improvement in the construction industry, and the specific impact of organisational resilience on construction project success needs to be further confirmed. The concept of resilience, which originates from complex system theories, has the potential to address the gaps in the body of knowledge of the construction project management field (Fraccascia et al., 2018). In the face of uncertainty and emergencies, hospitals and related buildings are often ar- 
eas that challenge the coping ability (Hugelius et al., 2020). Sapeciay's investigation found that the current construction industry, especially small and medium-sized enterprises in the construction industry, has not achieved good resilience practices (Sapeciay et al., 2017). The study also found that construction resilience requires better practitioner knowledge, standard practices and investment in industry capacity building. At the same time, relatively little research has been conducted on the organisational resilience that affect the success of construction project. Some researchers have also criticized resilience research for its lack of the concepts of empirical measurability and effectiveness (Aleksic et al., 2013; Linnenluecke, 2017).

\subsection{Measuring organizational resilience}

Although the concept of resilience is slightly different, the more consistent dimensions of resilience are adaptive capacity and vulnerability (Bhamra et al., 2011). Awareness (Huber et al., 2012; Øien, 2013) and efficiency (Bhamra et al., 2011; Huber et al., 2012) are also important dimensions. Through a case study, McManus et al. (2008) found that organisational resilience has three principal attributes: situation monitoring, management of keystone vulnerability and adaptive capacity. Stephenson (2010) proposed 13 index factors from the two dimensions of planning and adaptive capacity and constructed an evaluation model of organisational resilience. Whitman et al. (2013) proposed a short-form version of the Benchmark Resilience Tool based on the index factors proposed. Research scholars have laid the foundation of the development of organisational resilience indicators, but none of their studies have been specific to a particular industry or focused on the different characteristics of the construction industry. Moreover, the construction organisation itself consists of various organisations, such as construction clients, planners, architects, constructors, suppliers, consultants and sub-consultants, all of which are unique, different and complex in their organisational environment. Hence, to make the construction organisation benefit from the practice of improving organisational resilience, developing an evaluation tool for construction organisational resilience is necessary (Seville et al., 2006). According to the different characteristics of specific construction industry, Sapeciay et al. (2017) compared and analysed two different strategies for the resilience of New Zealand management organisations: Resilient Organisations (ResOrgs) and the Ministry of Civil Defence and Emergency Management (MCDEM) strategy. The purpose is to determine the importance of the indicators used in the assessment tools and evaluate the resilience of construction organisations.
Organisations need to balance external influences with internal resilience capabilities (Erol et al., 2010). With the transformation of the construction industry and the arrival of the big data era, the preconditions for the success of construction project have changed accordingly. Therefore, exploring the assessment index factors of construction project organisation resilience in the new era has become imperative. The current research on organisational resilience focuses on the field of emergency management in the discipline of public administration. Concerning the outbreak of the epidemic, we realize that the ability to respond to emergency events should be learned and used for reference in the field of engineering management. Building organisational resilience should encourage strong leadership, partnership and collaboration within the sector, across the sector and government boundaries (Wilkinson et al., 2016).

\section{Research method: Crisp-Set Qualitative Comparative Analysis}

\subsection{Introduction to csQCA}

As a research method, Qualitative Comparative Analysis (QCA) considers "configuration comparison" and "set theory". It is a new method that goes beyond qualitative and quantitative (Ragin et al., 2006). The method is based on cases and combined with computer algorithms to achieve comparative analysis between different cases and aids in the discovery of similarities and differences in cross-case systems. In terms of its principle, QCA is "results-driven". The method of evaluating "multiple concurrent causal relationships" is realized by identifying the causal path of different situational factors that lead to the same result. Compared with mainstream statistical methods, QCA infers causality by means of set relation. Moreover, Biernacki (1989) believed that set relation can provide important and clear information for social phenomena. Therefore, QCA is more suitable for this study to analyze multi case issues in combination with sociology. QCA technology includes crisp-set Qualitative Comparative Analysis (csQCA), fuzzy-set Qualitative Comparative Analysis (fsQCA) and multi-value Qualitative Comparative Analysis (mvQCA). Among these technologies, the csQCA is the most widely used QCA technology (Huarng \& Roig-Tierno, 2016). The current study uses this technology to analyse and explore the linkage effect. The csQCA is based on computer Boolean algebra to build complex operation set and uses Boolean Minimization Technology to simplify. The main operation steps are shown in Figure 1.

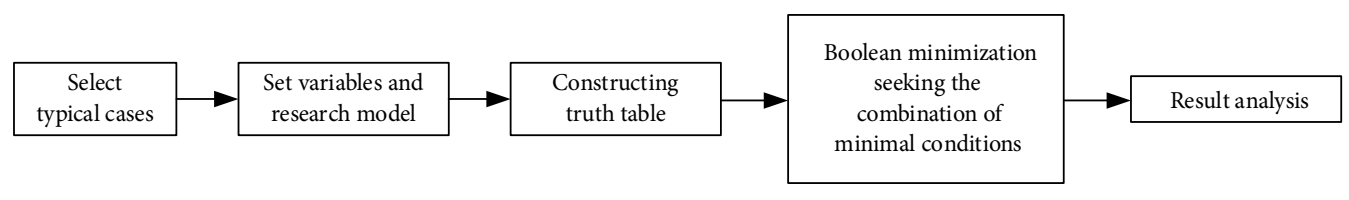

Figure 1. csQCA method flow chart 


\subsection{Selection of typical cases}

QCA does not require a high sample size. It can use 1580 sample sizes and has a greater advantage in the study of small and medium-sized samples whose variables are composed mainly of binary forms (Ragin, 1987). According to Marx et al. (2013), 5\% was set as the threshold. With four conditions set in this study, 15 cases are suitable as acceptable benchmarks. The typical case selection steps are as follows: first, 103 cases are collected from the provinces and cities across the country as the first-level alternative case database; second, the typical case database is selected and determined according to the principles set by this study; and finally, the supporting materials for the case are searched, expanded and sorted, and then compared repeatedly and confirmed through the triangle test method to form the final case library required for this study.

The selection of typical cases follows the succeeding principles:

(1) Based on the above understandings of organisational resilience of construction projects, select cases that meet the standards.
(2) The selected case is representative, that is, it has great social influence and is a concern for the academia, media and society.

(3) The case supporting materials are comprehensive, and include internal publications, annual reports, academic databases, media reports, academic papers, forum posts, blogs, microblogs, open letters, symbolic slogans, press conferences, related videos and other types of materials, which are crosschecked by triangle verification method repeatedly to obtain high reliability.

Finally, 15 cases that meet the requirements (shown in Table 1) are selected as the case base for this study.

\subsection{Variables and research models}

Organisational resilience is not only a multi-level concept, but also a multi-dimensional concept. It is the result of the interaction between the organisation and the external environment (Andersson et al., 2019). Due to the ambiguity and uncertainty of the concept definition, scholars had relatively large differences in the division and measurement of organisational resilience dimensions.

Table 1. The base of 15 typical case

\begin{tabular}{|c|c|c|c|}
\hline $\begin{array}{c}\text { Num- } \\
\text { ber }\end{array}$ & Date & Project & Brief information \\
\hline 1 & 2020.1 & $\begin{array}{l}\text { Novel Coronavirus - } \\
\text { Leishenshan and } \\
\text { Huoshenshan Hospital }\end{array}$ & $\begin{array}{l}\text { In the face of social and public health events, both hospitals adopt container type } \\
\text { mobile houses, which reduces the construction period of traditional houses by } \\
40-60 \% \text {. The construction period of Huoshenshan hospital is } 6 \text { days, the installation } \\
\text { period is } 3 \text { days, and the delivery period of Leishenshan hospital is } 10 \text { days, which has } \\
\text { aroused social repercussions. }\end{array}$ \\
\hline 2 & 2018.10 & $\begin{array}{l}\text { Hong Kong-Zhuhai- } \\
\text { Macao Bridge }\end{array}$ & $\begin{array}{l}\text { The Hong Kong Zhuhai Macao Bridge has ultra-high standards in road design, } \\
\text { service life, anti-collision and earthquake prevention, flood and wind resistance. It has } \\
\text { overcome more than ten world-class technical problems, driven the construction of } \\
20 \text { bases and production lines, formed the core technology with China's independent } \\
\text { intellectual property rights and established China's Cross Sea channel construction } \\
\text { industrial technology system. }\end{array}$ \\
\hline 3 & 2016.11 & $\begin{array}{l}\text { Construction Platform } \\
\text { Collapse of Cooling } \\
\text { Tower in Jiangxi } \\
\text { Fengcheng Power Plant }\end{array}$ & $\begin{array}{l}\text { After receiving the police situational report, Jiangxi provincial public security fire } \\
\text { brigade immediately launched the cross-regional emergency rescue and reinforcement } \\
\text { plan and mobilized four fire brigades and the full-service headquarters of the brigade } \\
\text { at one time. Four measures have implemented to carry out rescue operations: } \\
\text { reconnaissance and understanding to grasp the disaster situation; determination of the } \\
\text { key points and full efforts to search and rescue; safety monitoring to prevent secondary } \\
\text { disasters; and division of areas and work in groups. }\end{array}$ \\
\hline 4 & 2008.5 & $\begin{array}{l}\text { Reconstruction after the } \\
\text { Wenchuan Earthquake }\end{array}$ & $\begin{array}{l}\text { The post-disaster reconstruction took four years, with an investment of more than } 800 \\
\text { billion yuan, and the earthquake-stricken area was reborn. }\end{array}$ \\
\hline 5 & 2008.4 & $\begin{array}{l}\text { Beijing-Shanghai High- } \\
\text { speed Railway }\end{array}$ & $\begin{array}{l}\text { High speed, high density and high reliability are the core of high-speed railway } \\
\text { technology. China has completed more than } 400 \text { scientific research studies have } \\
\text { overcome a series of technical problems for the successful construction of the Beijing- } \\
\text { Shanghai high-speed railway. }\end{array}$ \\
\hline 6 & 2008.3 & Bird's Nest & $\begin{array}{l}\text { The "Bird's Nest" has dozens of innovative technologies and is one of the most difficult } \\
\text { steel structure projects in the world. Using reliable, mature and advanced high-tech } \\
\text { achievements, the National Stadium has been built into an advanced venue with } \\
\text { people-oriented information services and convenient and reliable communication } \\
\text { methods, realizing huge challenges in a limited time. }\end{array}$ \\
\hline 7 & 2006.7 & Qinghai-Tibet Railway & $\begin{array}{l}\text { Most of the lines of the Qinghai Tibet railway are in the high-altitude area and "life- } \\
\text { forbidden zone". The construction of the Qinghai Tibet railway faced three major } \\
\text { railway construction problems: the geological structure of permafrost for thousands of } \\
\text { miles, the environment of high cold and anoxic and the fragile ecology. }\end{array}$ \\
\hline
\end{tabular}


End of Table 1

\begin{tabular}{|c|c|c|c|}
\hline $\begin{array}{c}\text { Num- } \\
\text { ber }\end{array}$ & Date & Project & Brief information \\
\hline 8 & 2003.6 & Hangzhou Bay Bridge & $\begin{array}{l}\text { In the process of construction, GPS all-weather operation survey control technology, } \\
\text { the durability of concrete structure in the marine environment and the influence } \\
\text { of disastrous weather on the safety of bridge driving were introduced. The project } \\
\text { successfully met the challenges of large quantities of bridge spacing, complex } \\
\text { construction conditions, high technology content and difficult management. }\end{array}$ \\
\hline 9 & 2002.11 & $\begin{array}{l}\text { SARS-Beijing } \\
\text { Xiaotangshan Hospital }\end{array}$ & $\begin{array}{l}\text { At the time of severe SARS, a special infectious disease hospital with a construction } \\
\text { area of } 25000 \text { square meters and } 1000 \text { beds was built in seven days and seven nights, } \\
\text { with a total of } 168 \text { hours, which is unprecedented in the world's architectural history. }\end{array}$ \\
\hline 10 & 1985.4 & Bank of China Tower & $\begin{array}{l}\text { Hong Kong is visited by many tropical storms and the wind is often twice as strong } \\
\text { as that of New York; thus, having sufficient and reliable technical guarantee for the } \\
\text { stability of tall buildings is necessary. }\end{array}$ \\
\hline 11 & 2005.12 & $\begin{array}{l}\text { Juxing bridge, Heping } \\
\text { County, Heyuan City, } \\
\text { Guangdong Province }\end{array}$ & $\begin{array}{l}\text { The bridge built with nearly } 370,000 \text { yuan of disaster relief funds was destroyed } \\
\text { by flooding before it was completed and accepted for inspection. The destruction } \\
\text { of Juxing bridge was not only due to the flood but also because the design and } \\
\text { construction and insufficient technical strength of the construction unit, improper site } \\
\text { selection, lax site management and quality problems of piers and beams. }\end{array}$ \\
\hline 12 & 2004.10 & CCTV Headquarters & $\begin{array}{l}\text { To meet the needs of modelling, the CCTV Headquarters Building challenged the } \\
\text { mechanics' principle and the bottom line of fire safety, which brought serious hidden } \\
\text { dangers to the safety of the structure and fire evacuation, as well as ultra-high } \\
\text { project cost. On February } 9,2009 \text {, a fire broke out in the TV Cultural Centre under } \\
\text { construction, which was extinguished nearly six hours later. }\end{array}$ \\
\hline 13 & 1999.3 & $\begin{array}{l}\text { Taiwan Longmen } \\
\text { Nuclear Power Plant }\end{array}$ & $\begin{array}{l}\text { During the construction of the power station, it was shut down many times due to } \\
\text { policy changes and the alternation of political parties. Later, due to the effects of } \\
\text { the Fukushima nuclear accident in Japan, residents and anti-nuclear groups blocked } \\
\text { constructions through protests, and the commercial operation date was postponed } \\
\text { indefinitely. }\end{array}$ \\
\hline 14 & 1994 & $\begin{array}{l}\text { Wonderland } \\
\text { Amusement Park }\end{array}$ & $\begin{array}{l}\text { In 1998, affected by the economic crisis in Southeast Asia, as well as developers, local } \\
\text { governments and villagers' differences in land value assessment and compensation, the } \\
\text { whole project was put on hold. In addition, the flood disaster in South China has led } \\
\text { to a debate on the protection of forest land. }\end{array}$ \\
\hline 15 & 1957 & $\begin{array}{l}\text { Three Gorges } \\
\text { Hydroelectric Power } \\
\text { Station }\end{array}$ & $\begin{array}{l}\text { The Three Gorges hydropower station has played an important role in flood control, } \\
\text { power generation and shipping, but from the environmental point of view, it failed } \\
\text { to make a full plan for ecological protection, resulting in the deterioration of water } \\
\text { quality, thereby causing infectious diseases. At the same time, the reservoir flooded the } \\
\text { cultural relics, and the cultural relics department began to rescue and excavate in } 1992\end{array}$ \\
\hline
\end{tabular}

From the perspective of organisation theory, organisational culture and organisational structure, as the two basic components that support the operation of the organisation, play a vital role in the survival and development of the organisation. Organisational structure indicates how work tasks are formally divided, categorized, and collaborated (Child, 1985). Organisational culture is regarded as a set of norms, attitudes, values and organisational models that constitute an organisation (Denison, 1984). Based on the literature review and the actual situation, this study extracts 10 organisational resilience factors that affect the success of construction projects, among which innovation and creativity, resource redundancy and planning strategies reflect the flexibility of organisational structure. Effective partnerships, information disclosure and organisational cohesion reflect the values of the organisation and highlight the organisational culture. On the basis of full consideration and analysis of previous studies, this study seeks the organisational resilience conditions that promote the success of construction project, and constructs a research model with situation monitoring, organisational structure, organisational culture and participants as four conditional variables and one outcome variable, as shown in Figure 2.

\subsubsection{Situation monitoring}

Scenario monitoring is the creation, management and monitoring of human and mechanical sensors that continuously identify and characterize the internal and external environments of an organisation to find weak signals of a crisis or emergency (Stephenson, 2010). Situation monitoring is divided into two indicators: situation awareness and digital application.

(1) Situation awareness, which was first applied to the military, is defined as understanding of what is going on around you and what that information means to you now and in the future (Endsley, 2003). Situation awareness should be regarded as the basic requirement for competence in a dynamic environment, which usually leads to dangerous and life-threatening consequences under inaccurate and incomplete situation awareness (Masys, 2005). 


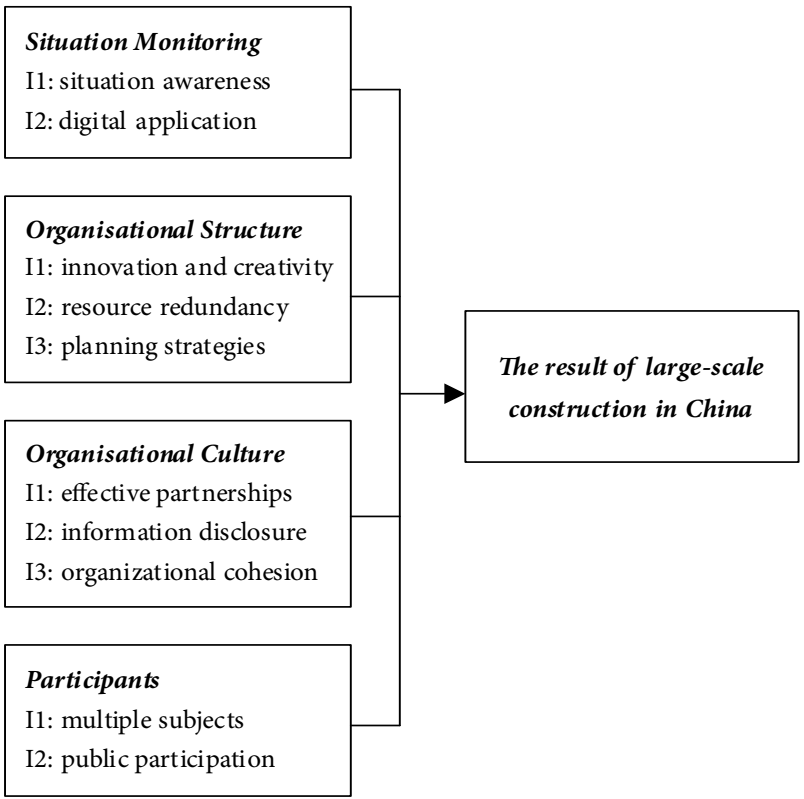

Figure 2. Research model of organisational resilience factors of construction project

The construction project itself is complex, and in a complex social environment, situation awareness is also the key to promote the success of construction project.

(2) Digital application in situation monitoring is the general development direction in the future (Edirisinghe, 2019). The construction site is a place where people gather. In addition, the risk of infection in this epidemic is high. Through "face recognition + temperature measurement module + solution", it can realize the need for automatic monitoring, early warning and control of people with abnormal temperature, eliminate the risk of infection in time and reduce the management difficulty of managers. The digital application in construction project undoubtedly provides a feasible solution to solve the problems such as data barriers, poor information and slow emergency response, so as to promote the success of construction project.

\subsubsection{Organisational structure}

Organisational structure refers to the formal design of roles and management mechanisms in an organisation to control and integrate work activities and resource flows (Olson et al., 1995). The organisational structure is divided into three indicators in this study: innovation and creativity, resource redundancy and planning strategies.

(1) Traditional organisational theory (Raub, 2008) holds that organisations with higher formalisation levels may promote organisational rigidity and hinder organisational flexibility, thereby reducing innovation motivation and organisational innovation. However, the modern organisation theory believes that formalisation does not mean rigidity because it has both rigidity and flexibility (Levinthal \& Rerup, 2006). Flexible and innovative organisational structures are essential in emergencies. For example, functional decentralization, that is, bureaucracy and decentralization carried out at the same time, helps organisations become decentralized when certain events require rapid decision-making (Clarke, 1993). Hamel and Välikangas (2003) believed that in the context of resilience, the survival of an organisation depends on its mastery of three types of innovation: revolution, renewal and resilience. In the transformation and upgrading of the construction industry, continuous innovation and reform of management methods and decision-making procedures are the hard truth of development.

(2) Redundancy refers to the ability to perform tasks when the main unit fails (LaPorte \& Consolini, 1991). The organisational structure needs to manage and mobilise the organisation's material, human and process resources to ensure that they can respond effectively to the changes in the organisation's operating environment before and after a crisis or emergency. Under the complex social background, construction projects are affected by natural disasters and social public events. Resource redundancy is a powerful guarantee for the success of construction project.

(3) The organisation should also have a planning strategy to face the emergency in advance, seize the opportunity in the difficulties and turn the results from adversity to prosperity (Penrose, 2000). For example, voluntary resources add value to disaster relief organisations if they are ready to manage those efforts. However, without preparation, these efforts will bring more problems to the already stretched organisations (Zhang et al., 2018). Also, in construction projects, crises cannot be avoided, and a good planning strategy can reduce the damage and loss caused by crises to a certain extent.

\subsubsection{Organisational culture}

Organisational culture is the sum of group consciousness, such as basic beliefs, ways of thinking, ways of behaviour and values shared by organisational members and regarded as effective when organisations solve the problems of external adaptation and internal integration (Schein, 1989). The organisation has resilience only when organisational resilience is rooted in the organisational culture (Elwood, 2009). Organisational culture is divided into three indicators in this study: effective partnerships, information disclosure and organisational cohesion.

(1) In a crisis, organisations are often unaware of the full potential effects of bad relationships (Mcmanus, 2008). An effective partnership helps participants to become the common strength of the organisation. The construction project itself is composed 
of many stakeholders. The success of the construction project is bound to require the joint efforts of all stakeholders. Effective partnerships help to promote the unity of objectives and win-win cooperation.

(2) Manage and share information and knowledge between organisations to ensure that people who make decisions in a crisis or emergency have as much useful information as possible. The organisational practice of information disclosure enables more subjects to understand the progress and truth of events, participate in the organisation and make the organisation's accountability and governance mechanism more transparent. Information disclosure can accelerate decision-making and reduce the opportunistic behavior of stakeholders in construction projects caused by information asymmetry, so as to promote the success of construction project.

(3) Silo mentality is intertwined with organisational culture and creates an environment in which the personal and departmental interests of managers may take priority over organisational well-being (Stone, 2010). Hence, employees should be encouraged to move between different departments or try different roles to gain experience, thereby breaking the silo mentality and increasing organisational cohesion (Brown et al., 2017). In the construction project, the flow of professional and technical personnel and professional exchange are strengthened, which enhances the organisational cohesion, and also helps the success of the project.

\subsubsection{Participants}

In the construction of major infrastructure, reconstruction after major disasters and challenging construction, the participants involved are limited to one construction project, but also need the joint participation of multiple central subjects and establish a good interaction mechanism and platform to enable the government, market and society can play their respective roles well. At the same time, they can also through consultation, negotiation, cooperation and other ways to complement and cooperate to achieve rapid recovery or complete challenging tasks.

Public participation is emphasized in the multi-subject participation of construction project ( $\mathrm{Li}$ et al., 2013). The organisational resilience of construction project should give play to the strength and advantages of interdisciplinarity, take the public needs and participation as the starting point, and fully integrate studies on the allocation of social resources and network connections to create construction project with overall organisational resilience. The rapid development of civil society and the vigorous rise of information technology enable the public to play an important role in public events. Similarly, multiple subjects and public participation will also be the key factors to promote the success of construction project. Therefore, this study divides participants into two indicators: multiple subjects and public participation.

\subsubsection{The result of large-scale construction in China}

In this study, the result of large-scale construction project in China is taken as outcome variable. The success of the project is not limited to the common achievement of the three goals of schedule, quality and cost, which is the result of the effective and efficient realization of the project. From the perspective of result dimension, project success also includes the realization of corresponding benefits brought by the project and the satisfaction of stakeholders with the products delivered by the project; from the perspective of process dimension, the project needs to ensure the success of project function, economy, society, safety and environmental protection. For example, CCTV Headquarters, even if the final deliverables were successful, but from the perspective of organisational resilience of the whole life cycle, the risks brought by the unique design of the project in the construction process and the public opinion after the deliverables were not successful. However, like the collapse of the Jiangxi Fengcheng cooling platform, which was a failed project for the incident itself, but from the perspective of the resilience of the construction project, the rapid response to the emergencies and the positive response measures were successful. It can be seen from the case that the status of the four independent variables of situation monitoring, organisational structure, organisational culture and participants is inevitable related to the success of the construction project.

\subsection{Data collection}

This study not only determines whether each case contains the above organisational resilience indicators through rigorous data collection, such as statistical yearbooks, news reports, etc. but also considers the more authentic direct feedback of each construction project. Project managers, experts from consultancy and other stakeholders conducted in-depth interviews and questionnaires, and their basic information is shown in Table 2. For 15 cases, each

Table 2. Respondent characteristics information

\begin{tabular}{|c|c|c|c|}
\hline Item & Type & Frequency & Percentage \\
\hline \multirow{4}{*}{$\begin{array}{l}\text { Education } \\
\text { level }\end{array}$} & High school and below & 5 & 9.43 \\
\hline & College & 15 & 28.30 \\
\hline & Undergraduate & 23 & 43.40 \\
\hline & Master degree or above & 10 & 18.87 \\
\hline \multirow{4}{*}{$\begin{array}{l}\text { Work } \\
\text { experience }\end{array}$} & $<3$ years & 8 & 15.09 \\
\hline & $3-5$ years & 15 & 28.30 \\
\hline & $6-10$ years & 21 & 39.62 \\
\hline & $>10$ years & 9 & 16.98 \\
\hline \multirow{4}{*}{$\begin{array}{l}\text { Participant } \\
\text { role }\end{array}$} & $\begin{array}{l}\text { Experts from } \\
\text { consultancy }\end{array}$ & 18 & 33.96 \\
\hline & Project manager & 15 & 28.30 \\
\hline & Department manager & 11 & 20.75 \\
\hline & $\begin{array}{l}\text { Professional and } \\
\text { technical personnel }\end{array}$ & 9 & 16.98 \\
\hline
\end{tabular}


case involved 2-5 respondents, and ultimately a total of 53 respondents. There are two main sources of information from the interviewees: (1) Organisational resilience factors of the construction project involved in the case project, (2) Judging the success and failure of the project from the perspective of organisational resilience.

Based on the research of Ahuja et al. (2017), this study used a five-point Likert scale from 1 (strongly disagree) to 5 (strongly agree), which improved the accuracy and objectivity of the original data. The stakeholders involved in each case rated the organisational resilience indicators involved in the case (see Table 3 ). First, the indicators under each variable are assigned a binary value of 1,0 . The indicator with score greater than or equal to 4 is assigned to 1 , and the indicator with score less than or equal to 3 is assigned to 0 (Mastrangelo et al., 2017) (see Table 4). Second, in this study, if the case contains one or more indicators under the variable, binary value 1 is assigned to the variable. Instead, if none of the cases contain any indicators under the variable, the binary value 0 is assigned to the variable.

Moreover, according to the outcome variables of 15 cases, the project managers, stakeholders and experts involved in the cases were discussed from the perspective of organisational resilience for many times to determine the success and failure of the project. On the basis of objective and real data, through many expert interviews and on-the-spot investigation, the subjective reality was taken into account, and finally a more practical result judgment was made. Among them, 10 cases were identified as success cases and 5 cases as failure cases. In order to analyse the result data more clearly in the future, the 10 successful cases are cases 1-10, and the failed cases are cases 11-15.

\subsection{Constructing truth table}

The analysis unit of QCA operation is a conditional combination rather than a case. Hence, all combinations of a condition variable and result variable will be obtained after specific assignment of each variable that is, truth table (Schneider et al., 2019). This study has 10 factors in four dimensions. If one or more indicator factors appear in each condition, a binary value of 1 is specified for a case. If no metric factor is shown for each condition, the binary value 0 is assigned to the case. For the outcome variable, 10 success cases are assigned as 1 and 5 failure cases are assigned as 0 . Finally, the truth tables of 15 cases are calculated using the software Tosmana1.61, as shown in Table 5. The truth table can be represented more intuitively by a Venn diagram, as shown in Figure 3.

\section{Research results and analysis}

\subsection{Necessity analysis of single variable}

In csQCA, the consistency index is generally used to analyse the necessity and sufficiency of a single variable (Ragin, 2006). Consistency can explain the extent to which the analysed cases have the conditions or conditional configurations for the results at the same time. After the judgment of sufficient or necessary conditions is completed, the strength of the interpretation of the condition variables to the result variable can be judged further by the coverage. Through calculation, the consistency and coverage of the four single variables are listed in Table 6 . If a single condition or combination of conditions is a sufficient condition for the result, the corresponding consistency index should be greater than 0.8 . Similarly, if the consistency index is greater than 0.9 , a certain condition or combination of conditions can be judged as a necessary condition for the result.

The results show that the variable score of "participants" is higher than 0.8 but less than 0.9 , which can be regarded as a sufficient condition, that is to say, the multiple subjects and public participation can promote the success of the construction project to some extent, but the sufficient condition alone cannot be regarded as the necessary condition. Although the consistency and coverage of other condition variables are not low, it can only explain that they have certain explanatory power to the occurrence of results and cannot be taken as a sufficient or necessary condition for the occurrence of results. Given that the results of construction projects are "multiple complex concurrent cause and effect", further analysis of the combination of condition variables is needed to obtain more information.

\subsection{Conditional combination analysis}

Based on the necessity analysis of single variable, the study further analyses the conditional configurations of organisational resilience that promote the success of construction projects, and finally obtains the following conditional configurations, as shown in Figure 4. The qualitative analysis results of condition combination are shown in Table 6.

Table 7 shows that although the raw coverage between the two combinations is different, the consistency of each combination is $100 \%$, which indicates that $\mathrm{OS}^{\star} \mathrm{OC}^{\star} \mathrm{P}$ and $\mathrm{SM}^{\star} \mathrm{OS}^{\star} \mathrm{P}$ are fully sufficient for the success of the construction project. In this regard, the two paths are analysed concretely.

Path 1: Construction project success $=$ Organisational Structure ${ }^{\star}$ Organisational Culture ${ }^{\star}$ Participants. The raw coverage of this path is 0.80 , which indicates that $80 \%$ of the successful construction project cases can be explained by this path. The condition configuration refers to the flexible organisational structure, cohesive organisational culture and multi-subject participation, which can promote the success of construction projects in the face of crisis events, natural risks, environmental uncertainties and increasing challenges. Detecting a crisis and predicting the uncertainty of future events in time can be limited and difficult. Therefore, timely and effective response measures and multi-agent joint response can also promote the success of construction projects. For example, the construction platform collapse of a cooling tower in 
Table 3. Organisational resilience indicator results of each case

\begin{tabular}{|c|c|c|c|c|c|c|c|c|c|c|}
\hline \multirow{2}{*}{ Numbers } & \multicolumn{2}{|c|}{$\begin{array}{l}\text { Situation Monitoring } \\
(\mathrm{SM})\end{array}$} & \multicolumn{3}{|c|}{$\begin{array}{l}\text { Organisational Structure } \\
\text { (OS) }\end{array}$} & \multicolumn{3}{|c|}{$\begin{array}{l}\text { Organisational Culture } \\
\text { (OC) }\end{array}$} & \multicolumn{2}{|c|}{$\begin{array}{l}\text { Participants } \\
\text { (P) }\end{array}$} \\
\hline & I1 & $\mathrm{I} 2$ & I1 & $\mathrm{I} 2$ & I3 & I1 & $\mathrm{I} 2$ & $\mathrm{I} 3$ & I1 & $\mathrm{I} 2$ \\
\hline Case 1 & 4.50 & 4.50 & 3.00 & 3.50 & 4.00 & 3.50 & 4.00 & 4.50 & 4.50 & 4.00 \\
\hline Case 2 & 4.00 & 4.50 & 4.00 & 2.50 & 4.00 & 3.50 & 3.50 & 3.50 & 4.00 & 2.00 \\
\hline Case 3 & 2.00 & 2.33 & 1.67 & 1.67 & 3.67 & 4.33 & 2.67 & 3.67 & 4.00 & 2.00 \\
\hline Case 4 & 2.50 & 2.00 & 2.50 & 4.00 & 3.50 & 3.50 & 3.50 & 4.50 & 4.00 & 4.00 \\
\hline Case 5 & 3.50 & 4.00 & 4.00 & 3.50 & 3.50 & 3.00 & 2.00 & 3.00 & 3.50 & 1.50 \\
\hline Case 6 & 3.67 & 4.00 & 4.00 & 4.00 & 4.33 & 3.00 & 3.00 & 3.00 & 4.00 & 2.33 \\
\hline Case 7 & 4.50 & 4.00 & 3.50 & 3.50 & 4.50 & 3.50 & 3.50 & 4.00 & 4.00 & 2.00 \\
\hline Case 8 & 3.50 & 4.00 & 4.00 & 3.50 & 4.00 & 3.50 & 2.50 & 3.50 & 3.50 & 1.50 \\
\hline Case 9 & 3.00 & 2.33 & 1.67 & 4.33 & 4.67 & 4.00 & 4.33 & 4.67 & 4.33 & 3.67 \\
\hline Case 10 & 3.50 & 4.00 & 4.00 & 3.50 & 3.50 & 3.50 & 2.50 & 3.50 & 3.50 & 2.00 \\
\hline Case 11 & 1.50 & 1.50 & 1.00 & 3.50 & 3.50 & 3.50 & 2.00 & 2.50 & 2.00 & 1.00 \\
\hline Case 12 & 2.00 & 3.50 & 4.00 & 3.50 & 3.50 & 3.00 & 3.50 & 3.50 & 2.00 & 1.00 \\
\hline Case 13 & 1.50 & 2.00 & 2.00 & 3.50 & 2.00 & 2.00 & 1.50 & 1.50 & 3.50 & 1.00 \\
\hline Case 14 & 2.00 & 2.00 & 1.50 & 3.00 & 2.00 & 2.00 & 2.00 & 3.50 & 3.50 & 1.00 \\
\hline Case 15 & 3.50 & 4.00 & 3.50 & 3.50 & 3.00 & 2.50 & 3.00 & 2.50 & 2.00 & 1.00 \\
\hline
\end{tabular}

Table 4. Organisational resilience indicator results of each case

\begin{tabular}{|c|c|c|c|c|c|c|c|c|c|c|c|}
\hline \multirow[t]{2}{*}{ Numbers } & \multicolumn{2}{|c|}{$\begin{array}{l}\text { Situation Monitoring } \\
(\mathrm{SM})\end{array}$} & \multicolumn{3}{|c|}{$\begin{array}{l}\text { Organisational Structure } \\
\text { (OS) }\end{array}$} & \multicolumn{3}{|c|}{$\begin{array}{c}\text { Organisational Culture } \\
\text { (OC) }\end{array}$} & \multicolumn{2}{|c|}{$\begin{array}{l}\text { Participants } \\
\text { (P) }\end{array}$} & \multirow[t]{2}{*}{ Outcome } \\
\hline & I1 & I2 & I1 & $\mathrm{I} 2$ & I3 & I1 & $\mathrm{I} 2$ & I3 & I1 & $\mathrm{I} 2$ & \\
\hline Case 1 & 1 & 1 & 0 & 1 & 1 & 1 & 1 & 1 & 1 & 1 & 1 \\
\hline Case 2 & 1 & 1 & 1 & 0 & 1 & 1 & 1 & 1 & 1 & 0 & 1 \\
\hline Case 3 & 0 & 0 & 0 & 0 & 1 & 1 & 0 & 1 & 1 & 0 & 1 \\
\hline Case 4 & 0 & 0 & 0 & 1 & 1 & 1 & 1 & 1 & 1 & 1 & 1 \\
\hline Case 5 & 1 & 1 & 1 & 1 & 1 & 0 & 0 & 0 & 1 & 0 & 1 \\
\hline Case 6 & 1 & 1 & 1 & 1 & 1 & 0 & 0 & 0 & 1 & 0 & 1 \\
\hline Case 7 & 1 & 1 & 1 & 1 & 1 & 1 & 1 & 1 & 1 & 0 & 1 \\
\hline Case 8 & 1 & 1 & 1 & 1 & 1 & 1 & 0 & 1 & 1 & 0 & 1 \\
\hline Case 9 & 0 & 0 & 0 & 1 & 1 & 1 & 1 & 1 & 1 & 1 & 1 \\
\hline Case 10 & 1 & 1 & 1 & 1 & 1 & 1 & 0 & 1 & 1 & 0 & 1 \\
\hline Case 11 & 0 & 0 & 0 & 1 & 1 & 1 & 0 & 0 & 0 & 0 & 0 \\
\hline Case 12 & 0 & 1 & 1 & 1 & 1 & 0 & 1 & 1 & 0 & 0 & 0 \\
\hline Case 13 & 0 & 0 & 0 & 1 & 0 & 0 & 0 & 0 & 1 & 0 & 0 \\
\hline Case 14 & 0 & 0 & 0 & 0 & 0 & 0 & 0 & 1 & 1 & 0 & 0 \\
\hline Case 15 & 1 & 1 & 1 & 1 & 0 & 0 & 0 & 0 & 0 & 0 & 0 \\
\hline
\end{tabular}

Table 5. Truth table

\begin{tabular}{|l|c|c|c|c|c|}
\hline Case Numbers & SM & OS & OC & P & Outcome \\
\hline $1,2,7,8,10$ & 1 & 1 & 1 & 1 & 1 \\
\hline $3,4,9$ & 0 & 1 & 1 & 1 & 1 \\
\hline 5,6 & 1 & 1 & 0 & 1 & 1 \\
\hline 11 & 0 & 1 & 1 & 0 & 0 \\
\hline 12 & 1 & 1 & 1 & 0 & 0 \\
\hline 13 & 0 & 1 & 0 & 1 & 0 \\
\hline 14 & 0 & 0 & 1 & 1 & 0 \\
\hline 15 & 1 & 1 & 0 & 0 & 0 \\
\hline
\end{tabular}

Table 6. Necessity analysis result of single condition variable

\begin{tabular}{|c|c|c|}
\hline Single variable & Consistency & Coverage \\
\hline SM & 0.7778 & 0.70 \\
\hline OS & 0.7143 & 1.00 \\
\hline OC & 0.7273 & 0.80 \\
\hline P & 0.8333 & 1.00 \\
\hline
\end{tabular}


Jiangxi Fengcheng power plant, the reconstruction after the Wenchuan earthquake and the Beijing Xiaotangshan Hospital in this study are all in line with such conditional configurations that can respond actively to emergencies, realize the rapid reconstruction of construction projects and promote the resolution of incidents.

Path 2: Construction project success = Situation Monitoring ${ }^{\star}$ Organisational Structure ${ }^{\star}$ Participants. The raw coverage of this path is 0.70 , indicating that $70 \%$ of the successful construction project cases can be explained by this path. The conditional configuration refers to the flexible organisational structure, perfect planning strategy, sufficient resource supply and the cooperation of multiple subjects, which can also promote the success of the construction project under the premise of realizing that the construction project has greater risks and challenges. Even if the construction project itself does not have an organisational culture of information openness, transparency, coordination of organisational relationships and strong cohesion, the participation and attention of various subjects and the public from all walks of life results in the breaking of the communication barriers between various stakeholders of the project thereby enabling all stakeholders to have goal consistency. For example, the Beijing-
Shanghai high-speed railway and Bird's Nest in this study meet this kind of conditional configuration; such projects had ultra-high challenges and complexity, involved many stakeholders and could not be integrated only by the implicit role of organisational culture. Currently, the attention of the public and society and the multi-disciplinary cooperation cause construction projects to have strong objectives.

\section{Discussion}

By using the crisp-set Qualitative Comparative Analysis method to analyse the research results of 15 cases, different conditional configurations have yielded the following points.

First, the role of multi-subject participation and public participation in complex construction projects has become increasingly prominent. The construction project itself is a complex system that pursues the maximization of collective efficiency, multi-subject coordination and the balance of the whole process to promote the success of the construction project effectively. Construction projects are in an open social background and different actors will have different values and interests, making it difficult to adapt

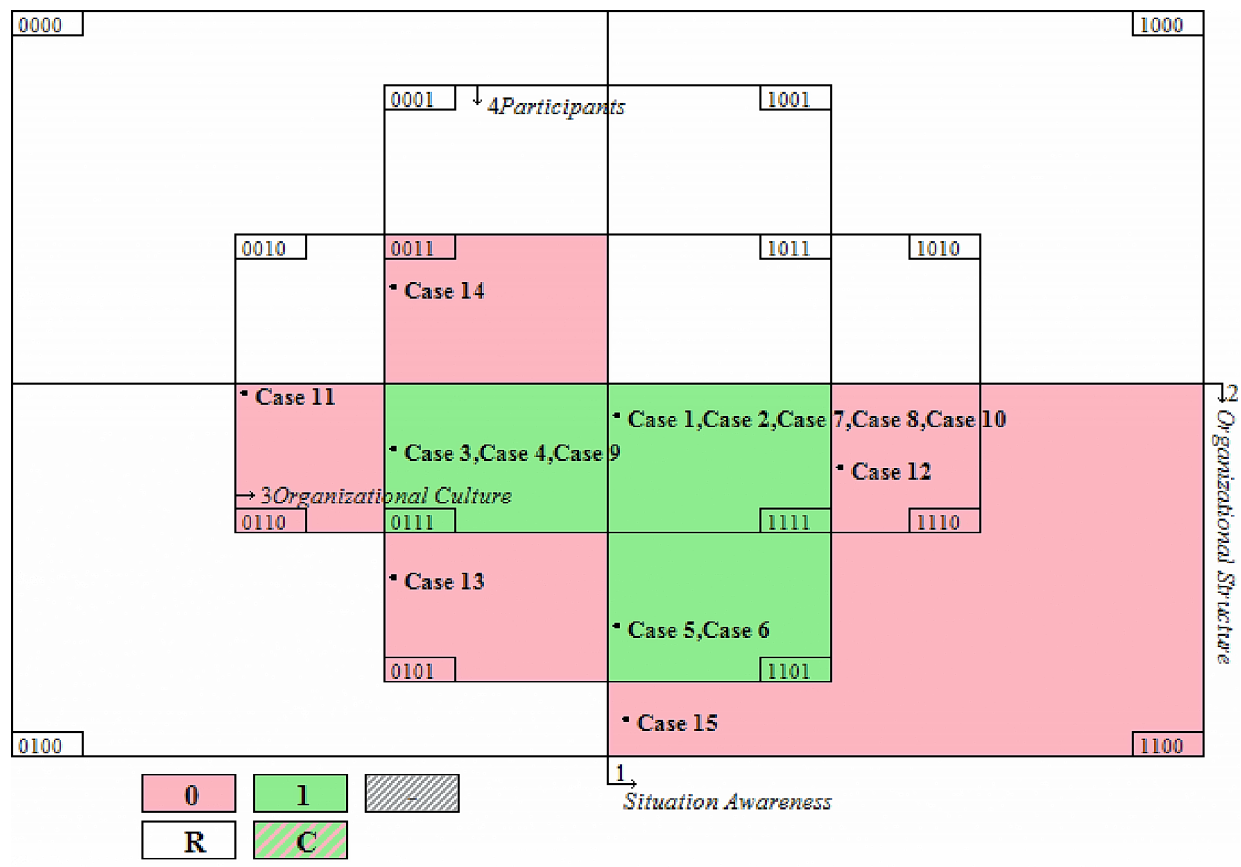

Figure 3. Venn diagram of 15 cases

Table 7. Qualitative comparative analysis of conditional configuration

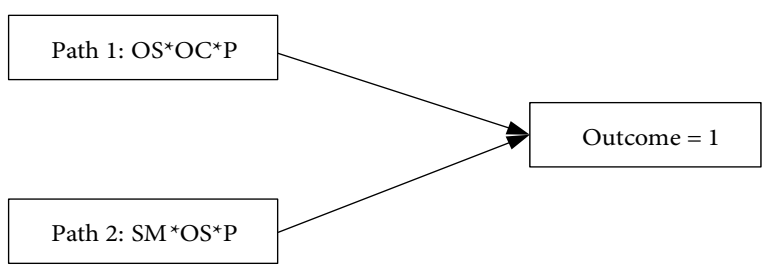

Figure 4. Conditional combination path

\begin{tabular}{|l|c|c|c|}
\hline $\begin{array}{c}\text { Conditional } \\
\text { configuration }\end{array}$ & $\begin{array}{c}\text { Raw } \\
\text { coverage }\end{array}$ & $\begin{array}{c}\text { Unique } \\
\text { coverage }\end{array}$ & Consistency \\
\hline $\mathrm{OS}^{\star} \mathrm{OC}^{\star} \mathrm{P}$ & 0.80 & 0.30 & 1.00 \\
\hline $\mathrm{SM}^{\star} \mathrm{OS}^{\star} \mathrm{P}$ & 0.70 & 0.20 & 1.00 \\
\hline Solution coverage: 1.00 \\
\hline
\end{tabular}


to the extreme challenges of construction project resources and technology by a single subject. Public participation is emphasized in multi-subject participation. On the one hand, the public's right to know, participate, express and supervise should be fully respected to promote transparency of information disclosure and decision-making. At the same time, public feedback should be understood to strengthen quality and progress management. As far as the emergency response to the new coronary pneumonia epidemic is concerned, public opinion and social mentality monitoring are crucial. On the other hand, the public plays an important coordination role in resource scheduling to compensate for the shortage of resources.

Second, the overall resilience of the organisation can be improved by the reasonable allocation of the resilience factors. Driven by strong real needs, regardless of the subject knowledge, if it is helpful to meet the real needs, it can be "used for me". It is in this sense that the organisational resilience of construction projects should emphasize multidisciplinary intersection and interdisciplinary integration. In this study, organisational resilience factors are divided into four dimensions: situation monitoring, organisational structure, organisational culture and participants. Situation monitoring emphasizes monitoring, and the latter three emphasize response mechanism. The transformation and upgrading of the construction industry have given rise to the necessity to explore new resilience factors. For example, monitoring remains relatively weak in general, but the extensive application of big data and face recognition technology has resulted in significant improvement in the monitoring ability of security events, which forms a supplement to the existing investigation methods. With the popularization of big data technology and the normalization of monitoring, it has become one of the main mechanisms for the organisation and implementation of construction projects. However, after the emergency response is started, the monitoring needs to continue, which is also a response mechanism.

Enhancing the organisational resilience of construction projects has also become an urgent necessity given the increasing challenges, environmental uncertainties and crises that have occurred. The construction project is also a complex adaptive system. The resilience of this system is the overall ability to determine whether a city, region or even a country can respond effectively to the crisis, challenge and recovery. A resilient construction project organisation should have important characteristics, such as autonomy, diversity, distribution, self-regulation, integration and adaptability. It also includes a comprehensive resource reserve system that combines the government and the market, a strong production, supply and logistics system, a clear and transparent responsibility system and regulatory system, and intelligent processing of information and data. A basic yet long-term task is increasing the organisational resilience of construction projects. The emphasis of the government and the public on the organisational resilience of construction projects has a "diminishing marginal return" effect. Facing the failure of construction projects, increasing organisational resilience is a means to easily obtain the consensus of the government and the public in the short term. However, with time, both the government's attention to the construction industry and the public's attention to construction project accidents have inevitably decreased, resulting in a lack of consensus and the inability to carry out post-crisis learning and pre-risk risk prevention. This constraint must be perceived and adapted in management practice.

Among the only literature conclusions on the organisational resilience of construction project, they mainly make theoretical contributions to the preliminary understanding and measurement indicators of the organisational resilience of construction project. Compared with previous literature conclusions, this study combines actual cases and considers from a sociological perspective to analyze the organisational resilience factors and different combinations of conditions that promote the success of construction project in a more targeted and real-time manner. And through the interdisciplinary, this study puts forward the public participation in the construction project implementation process, and puts forward the application of big data to the construction project in combination with the current era. The research results make up for the theoretical defects of increasing organisational resilience in construction project, and point out the direction for the future development of construction project.

\section{Conclusions}

Based on the literature review and the reality of the construction industry, this study abstracts four explanatory variables: situation monitoring, organisational structure, organisational culture and participants, including 10 organisational resilience factors. A crisp-set Qualitative Comparative Analysis is then used to analyse the selected 15 typical construction project cases that highlight organisational resilience. The intention is to identify the organisational resilience conditions and configuration conditions that affect the success of construction projects and provide a basis for effective guidance and control of construction projects in challenging and complex environments.

The results of csQCA not only illustrate the sufficiency and necessity of a single organisational resilience condition for the success of construction projects but also explore the combination of organisational resilience conditions that promote the success of construction projects. The research findings of this study are summarized as follows: (1) From a single conditional variable, it can be found that the "participants" variable is a single sufficient condition and not a necessary condition for the success of a construction project. The public's ability to resource scheduling and public opinion attitude monitoring should be introduced in future construction projects. (2) The configuration of $\mathrm{OS}^{\star} \mathrm{OC}^{*} \mathrm{P}$ is completely sufficient for the success of a construction project. When the risks, chal- 
lenges and environmental uncertainties of construction projects are not monitored in time and effectively, the response mechanism has a flexible organisational structure, cohesive organisational culture and multi-subject participation, which can also promote the success of construction projects actively and effectively. (3) The configuration of $\mathrm{SM}^{\star} \mathrm{OS}{ }^{*} \mathrm{P}$ is also sufficient for the success of the construction project. With situation monitoring, flexible organisational structure and multi-subject participation due to the cooperation of all sectors of the society and the close attention of the public, the cohesion and purpose of the construction project can be strengthened to a certain extent, making up for the lack of organisational culture. (4) Although situation monitoring, organisational structure and organisational culture are incompletely sufficient for the success of construction projects, they still have some explanatory power, which should be considered to increase the organisational resilience of construction projects in the future.

The innovation of this study lies in interdisciplinary research. From the perspective of sociology, this study applies the concepts of emergency management and public crisis in the field of public management to the field of engineering project management, thereby broadening the governance scenarios of construction projects and focusing on increasing the organisational resilience of construction projects. The theoretical description of resilience appears more in business management and organisation management, and the concept is more abstract. This study takes the temporary organisation of construction project as the research background, and combines abstract concepts with specific situations to make the resilience theory more practical and applicable. While exploring the path analysis of strengthening the organisational resilience of construction projects, this study emphasizes the modern information application technology represented by big data applications, so as to realize comprehensive governance (Tan \& Narayan, 2019), and advocates the interactive and organic cooperation mode of multiple subjects, so as to form a multi-center governance structure in which each subject can play its main role. It has made a scientific contribution to the future development direction and followup research of the construction project.

This study also has certain limitations for the study of organisational resilience conditions that affect construction projects. For example, the number of cases that meet the requirements of this study is relatively limited, with some subjective and visual biases. In addition, csQCA has limitations in quantitative analysis, and other methods should be used to explore more details of each condition affecting the organisational resilience of construction projects. In the future, it will help to conduct a more in-depth analysis to find more valuable cases and key conditions to promote the transformation and upgrading of construction projects.

\section{Acknowledgements}

The views presented here are those of the authors and should not be taken as representative of the position or policy of the organisations involved. The authors are grateful for the reviewers' comments that helped to improve the paper.

\section{Funding}

This research received funding from Major Financial Application Projects of Shandong Province, China (CJ-2017- 04).

\section{Author contributions}

All authors have contributed equally to this work.

\section{Disclosure statement}

The authors declare that they have no conflicts of interest. The founding sponsors had no role in the design of the study, collection, analyses, and interpretation of data, writing of the manuscript, and in the decision to publish the results.

\section{References}

Abdullah, N. A. S., Noor, N. L. M., \& Ibrahim, E. N. M. (2013). Resilient organization: Modelling the capacity for resilience. In 2013 International Conference on Research and Innovation in Information Systems (pp. 319-324). IEEE. https://doi.org/10.1109/ICRIIS.2013.6716729

Ahuja, R., Sawhney, A., \& Arif, M. (2017). Driving lean and green project outcomes using BIM: A qualitative comparative analysis. International Journal of Sustainable Built Environment, 6(1), 69-80. https://doi.org/10.1016/j.ijsbe.2016.10.006

Aleksic, A., Stefanovic, M., Arsovski, S., \& Tadic, D. (2013). An assessment of organizational resilience potential in SME of process industry, the fuzzy approach. Journal of Loss Prevention in the Process Industries, 26(6), 1238-1245.

https://doi.org/10.1016/j.jlp.2013.06.004

Andersson, T., Caker, M., Tengblad, S., \& Wickelgren, M. (2019). Building traits for organizational resilience through balancing organizational structures. Scandinavian Journal of Management, 35(1), 36-45. https://doi.org/10.1016/j.scaman.2019.01.001

Bhamra, R., Dani, S., \& Burnard, K. (2011). Resilience: the concept, a literature review and future directions. International Journal of Production Research, 49(18), 5375-5393. https://doi.org/10.1080/00207543.2011.563826

Biernacki, R. (1989). The comparative method: Moving beyond qualitative and quantitative strategies. Charles C. Ragin. American Journal of Sociology, 95(3). https://doi.org/10.1086/229365

Bosher, L., Dainty, A., Carrillo, P., Glass, J., \& Price, A. (2007). Integrating disaster risk management into construction: a UK perspective. Building Research \& Information, 35(2), 163-177. https://doi.org/10.1080/09613210600979848 
Brown, C., Seville, E., \& Vargo, J. (2017). Measuring the organizational resilience of critical infrastructure providers: A New Zealand case study. International Journal of Critical Infrastructure Protection, 18, 37-49.

https://doi.org/10.1016/j.ijcip.2017.05.002

Child, J. (1985). Organization - A guide to problems and practice (2nd ed.). Harper and Row.

Clarke, L. (1993). Drs. Pangloss and Strangelove meet organizational theory: High reliability organizations and nuclear weapons accidents. Sociological Forum, 8(4), 675-689. https://doi.org/10.1007/BF01115218

Comfort, L. K. (1994). Risk and resilience: Inter-organizational learning following the Northridge Earthquake of 17 January 1994. Journal of Contingencies \& Crisis Management, 2(3), 157-170. https://doi.org/10.1111/j.1468-5973.1994.tb00038.x

Cook, R. I. (2014). Resilience and resilience engineering in health care. Joint Commission Journal on Quality \& Patient Safety, 40(8), 376-383.

https://doi.org/10.1016/S1553-7250(14)40049-7

de Kloet, J., Poell, T., Guohua, Z., \& Yiu Fai, C. (2019). The platformization of Chinese Society: infrastructure, governance, and practice. Chinese Journal of Communication, 12(3), 249256. https://doi.org/10.1080/17544750.2019.1644008

Dekker, S., \& Hollnagel, E. (2007). Resilience engineering: New firections for measuring and maintaining safety in complex systems. School of Aviation.

Denison, D. R. (1984). Bringing corporate culture to the bottom line. Organizational Dynamics, 13(2), 5-22. https://doi.org/10.1016/0090-2616(84)90015-9

Edirisinghe, R. (2019). Digital skin of the construction site Smart sensor technologies towards the future smart construction site. Engineering Construction and Architectural Management, 26(2), 184-223. https://doi.org/10.1108/ECAM-04-2017-0066

Elwood, A. (2009). Using the disaster crunch/release model in building organisational resilience. Journal of Business Continuity \& Emergency Planning, 3(3), 241-247.

Endsley, M. R. (2003). Designing for situation awareness: An approach to user-centered design. CRC Press.

https://doi.org/10.1201/9780203485088

Enserink, B., \& Koppenjan, J. (2007). Public participation in China: sustainable urbanization and governance. Management of Environmental Quality: An International Journal, 18(4), 459-474. https://doi.org/10.1108/14777830710753848

Erol, O., Sauser, B. J., \& Mo, M. (2010). A framework for investigation into extended enterprise resilience. Enterprise Information Systems, 4(2), 111-136.

https://doi.org/10.1080/17517570903474304

Fraccascia, L., Giannoccaro, I., \& Albino, V. (2018). Resilience of complex systems: State of the art and directions for future research. Complexity, Article ID 3421529.

https://doi.org/10.1155/2018/3421529

$\mathrm{Gu}, \mathrm{X}$. (2015). Construction and operation of public participation platform in land use planning in China. University of Electronic Science \& Technology China Press.

Haigh, R., \& Amaratunga, D. (2010). An integrative review of the built environment <discipline's $>$ role in the development of society's resilience to disasters. International Journal of Disaster Resilience in the Built Environment, 1(1), 11-24. https://doi.org/10.1108/17595901011026454

Hamel, G., \& Välikangas, L. (2003). The quest for resilience. Harvard Business Review, 81(9), 52.

Hatton, T., Seville, E., \& Vargo, J. (2012). Asia Pacific Economic Cooperation (APEC) project on the Canterbury Earthquake series and SME resilience. Report 7: Improving the resilience of SMEs: policy and practice in New Zealand. University of Canterbury. http://hdl.handle.net/10092/9490

Hillmann, J. (2020). Disciplines of organizational resilience: contributions, critiques, and future research avenues. Review of Managerial Science.

https://doi.org/10.1007/s11846-020-00384-2

Hollnagel, E., Woods, D., \& Leveson, N. (Eds). (2006). Resilience engineering: Concepts and precepts. CRC Press.

Huber, G. J., Gomes, J. O., \& Carvalho, P. V. (2012). A program to support the construction and evaluation of resilience indicators. Work, 41(Supplement 1), 2810-2816.

https://doi.org/10.3233/WOR-2012-0528-2810

Hugelius, K., Becker, J., \& Adolfsson, A. (2020). Five challenges when managing mass casualty or disaster situations: a review study. International Journal of Environmental Research and Public Health, 17(9), 3068.

https://doi.org/10.3390/ijerph17093068

Jin, Z., \& Mostafavi, A. (2014). A system-of-systems framework for performance assessment in complex construction projects. Organization, Technology and Management, 6(3), 10831093. https://doi.org/10.5592/otmcj.2014.3.2

Huarng, K.-H., \& Roig-Tierno, N. (2016). Qualitative comparative analysis, crisp and fuzzy sets in knowledge and innovation. Journal of Business Research, 69(11), 5181-5186. https://doi.org/10.1016/j.jbusres.2016.04.109

LaPorte, T. R., \& Consolini, P. M. (1991). Working in practice but not in theory: Theoretical challenges of "high-reliability organizations". Journal of Public Administration Research and Theory, 1(1), 19-48.

https://doi.org/10.1093/oxfordjournals.jpart.a037070

Levinthal, D., \& Rerup, C. (2006). Crossing an apparent chasm: Bridging mindful and less-mindful perspectives on organizational learning. Organization Science, 17(4), 502-513. https://doi.org/10.1287/orsc.1060.0197

Li, T. H. Y., Ng, S. T., \& Skitmore, M. (2013). Evaluating stakeholder satisfaction during public participation in major infrastructure and construction projects: A fuzzy approach. Automation in Construction, 29, 123-135.

https://doi.org/10.1016/j.autcon.2012.09.007

Linnenluecke, M. K. (2017). Resilience in business and management research: A review of influential publications and a research agenda. International Journal of Management Reviews, 19(1), 4-30. https://doi.org/10.1111/ijmr.12076

Marx, A., Cambré, B., \& Rihoux, B. (2013). Crisp-set qualitative comparative analysis in organizational studies. Research in the Sociology of Organizations, 38, 23-47.

https://doi.org/10.1108/S0733-558X(2013)0000038006

Masnavi, M. R., Gharai, F., \& Hajibandeh, M. (2019). Exploring urban resilience thinking for its application in urban planning: a review of literature. International Journal of Environmental Science and Technology, 16(1), 567-582. https://doi.org/10.1007/s13762-018-1860-2

Mastrangelo, L. M., Benitez, D. G., \& Cruz-Ros, S. (2017). How social entrepreneurs can influence their employees' commitment. Journal of Promotion Management, 23(3), 437-448. https://doi.org/10.1080/10496491.2017.1294878

Masys, A. J. (2005). A systemic perspective of situation awareness: An analysis of the 2002 mid-air collision over Überlingen, Germany. Disaster Prevention \& Management, 14(4), 548-557. https://doi.org/10.1108/09653560510618375

McManus, S., Seville, E., Vargo, J., \& Brunsdon, D. (2008). Facilitated process for improving organizational resilience. Natural Hazards Review, 9(2). https://doi.org/10.1061/(ASCE)1527-6988(2008)9:2(81) 
Mcmanus, S. T. (2008). Organisational resilience in New Zealand [PhD thesis]. University of Canterbury.

https://doi.org/10.26021/1351

Tan, H. C., \& Narayan, S. (2019). Adopting big data to forecast success of construction projects: A review. Malaysian Construction Research Journal, 6(1), 132-143.

Olson, E. M., Walker, O. C., \& Ruekert, R. W. (1995). Organizing for effective new product development: The moderating role of product innovativeness. Journal of Marketing, 59(1), 48-62. https://doi.org/10.1177/002224299505900105

Omidvar, M., Mazloumi, A., Mohammad Fam, I., \& Nirumand, F. (2017). Development of a framework for resilience measurement: Suggestion of fuzzy Resilience Grade (RG) and fuzzy Resilience Early Warning Grade (REWG). Work, 56(3), 463474. https://doi.org/10.3233/WOR-172512

Patriarca, R., Bergström, J., Di Gravio, G., \& Costantino, F. (2018). Resilience engineering: Current status of the research and future challenges. Safety Science, 102, 79-100. https://doi.org/10.1016/j.ssci.2017.10.005

Pellissier, R. (2010). The implementation of resilience engineering to enhance organizational innovation in a complex environment. International Journal of Business and Management, 6(1), 145-164. https://doi.org/10.5539/ijbm.v6n1p145

Penrose, J. M. (2000). The role of perception in crisis planning. Public Relations Review, 26(2), 155-171. https://doi.org/10.1016/S0363-8111(00)00038-2

Ragin, C. C. (1987). The comparative method: Moving beyond qualitative and quantitative strategies. Social Forces, 67(3), 123-129. https://doi.org/10.2307/2579563

Ragin, C. C. (2006). Set relations in social research: Evaluating their consistency and coverage. Political Analysis, 14(3), 291-310. https://doi.org/10.1093/pan/mpj019

Ragin, C. C., Drass, K. A., \& Davey, S. (2006). Fuzzy-set/qualitative comparative analysis 2.5. Department of Sociology, University of Arizona.

Rapaport, C., Hornik-Lurie, T., Cohen, O., Lahad, M., Leykin, D., \& Aharonson-Daniel, L. (2018). The relationship between community type and community resilience. International Journal of Disaster Risk Reduction, 31, 470-477.

https://doi.org/10.1016/j.ijdrr.2018.05.020

Raub, S. (2008). Does bureaucracy kill individual initiative? The impact of structure on organizational citizenship behavior in the hospitality industry. International Journal of Hospitality Management, 27(2), 179-186.

https://doi.org/10.1016/j.ijhm.2007.07.018

Sapeciay, Z., Wilkinson, S., \& Costello, S. B. (2017). Building organisational resilience for the construction industry New Zealand practitioners' perspective. International Journal of Disaster Resilience in the Built Environment, 8(1), 98-108. https://doi.org/10.1108/IJDRBE-05-2016-0020

Schein, E. H. (1989). Corporate culture and organizational effectiveness, by D. R. Denison. Human Resource Management, 28(4), 557-561. https://doi.org/10.1002/hrm.3930280408

Schneider, C., Vis, B., \& Koivu, K. (2019). Summary: set-analytic approaches, especially Qualitative Comparative Analysis (QCA). American Political Science Association Organized Section for Qualitative and Multi-Method Research, Qualitative Transparency Deliberation (Working Group Final Reports, Report III.4S). SSRN. https://doi.org/10.2139/ssrn.3333483

Seville, E., Brunsdon, D., Dantas, A., Masurier, J. L., Wilkinson, S., \& Vargo, J. (2006). Building organisational resilience: A summary of key research findings. University of Canterbury.
Stephenson, A. V. (2010). Benchmarking the resilience of organisations [PhD dissertation]. University of Canterbury. https://doi.org/10.26021/2859

Stone, F. (2010). Deconstructing silos and supporting collaboration. Employment Relations Today, 31(1), 11-18. https://doi.org/10.1002/ert.20001

Whitman, Z. R., Kachali, H., Roger, D., Vargo, J., \& Seville, E. (2013). Short-form version of the Benchmark Resilience Tool (BRT-53). Measuring Business Excellence, 17(3), 3-14. https://doi.org/10.1108/MBE-05-2012-0030

Wilkinson, S., Chang-Richards, A. Y., Sapeciay, Z., \& Costello, S. B. (2016). Improving construction sector resilience. International Journal of Disaster Resilience in the Built Environment, 7(2), 173-185. https://doi.org/10.1108/IJDRBE-04-2015-0020

Woods, D., \& Wreathall, J. (2008). Stress-strain plots as a basis for assessing system resilience (Chapter 12). In Resilience engineering perspectives: Vol. 1. Remaining sensitive to the possibility of failure (pp. 145-161). CRC Press.

Zhang, J., Wang, T., Fan, D., Zhang, J., \& Jiang, B. (2018). Medical response to the Tianjin explosions: lessons learned. Disaster Medicine and Public Health Preparedness, 12(3), 411-414. https://doi.org/10.1017/dmp.2017.64

Øien, K. (2013). Remote operation in environmentally sensitive areas: development of early warning indicators. Journal of Risk Research, 16(3-4), 323-336. https://doi.org/10.1080/13669877.2012.729523 